\title{
Application of Differential Evolution for Wind Turbine Micrositing
}

\author{
SHAFIQ-UR-REHMAN MASSAN*, ASIM IMDAD WAGAN**, MUHAMMAD MUJTABA SHAIKH***, \\ AND MUHAMMAD SALEH SHAH****
}

RECEIVED ON 04.11.2015 ACCEPTED ON 22.11.2016

\begin{abstract}
WTM (Wind Turbine Micrositing) has been an important topic of discussion in recent times. A number of Evolutionary Algorithms have been applied to the WTM problem. The DEA(Differential Evolution Algorithm) is used for a bi-constrained optimization for getting maximum power production at the least cost from a 2x2 km space. It is shown that the DEA performs comparably to the GA(Genetic Algorithms) for wind farm optimization. The optimal configuration obtained enlists the number of turbines, the cost of power generated as well as the power produced. Moreover, this study is augmented by comparison with past approaches by using the GA for the same purpose.
\end{abstract}

Key Words: Wind Turbine Micro-Siting, N.O. Jensen Model, Heuristics, Wind Turbine Optimization, Differential Evolution Algorithm, GeneticAlgorithm.

\section{INTRODUCTION}

1 sustainable and secure supply of energy can be produced from wind turbines. Recent advances have been pushing for increase in rotor swept area so that the turbines are able to work in lesser wind conditions as well. The wind farms can produce a varying number of power output based on the turbines spatial position in the wind farm. Traditional wind farm design relies on the straight up linear arrangement of the turbines. But it has been shown [1] that a number of times that the turbine position if modifies optimizes the power produced from the wind farms.

WET (Wind Energy Technology) of today has come a long distance from its early days a decade ago. It is cost effective and more efficient due to the wide spread use of composite materials and cutting edge technology. The present study is an endeavour to improve the efficiency by systematically or recursively reducing the cost and increasing the power production [2].

\footnotetext{
* Shaheed Zulfikar Ali Bhutto Institute of Science \& Technology, Karachi.

** Mohammad Ali Jinnah University, Karachi.

*** Department of Basic Sciences \& Related Studies, Mehran University of Engineering \& Technology, Jamshoro.

**** Government Saifee Zahabi Edhi College of Education, Karachi.
}

Mehran University Research Journal of Engineering \& Technology, Volume 36, No. 2, April, 2017 [p-ISSN: 0254-7821, e-ISSN: 2413-7219] 
A number of algorithms have been applied for the solution of the WTO (Wind Turbine Optimization) problem and the application of the DEA is another step in that direction. This work fills the gap in which the research carried out in this field has not yet explored the potential of the DEA.

Our work builds upon the work of a decade of research in this area as referenced in [3-12]. It is true that previous research on optimization of WTM was based on GAs but researchers have also tried other algorithms for the same problem and compared the results with GAs; for example: [13-14,1]. Literature shows that the results from other algorithms are in good comparison to those by GAs and in some instances are better [1]. Hence, in this work we have used DEA - which has encouraging stability properties as compared to GA for WTM.

The WTO problem was first tackled by Mosetti [15]. He based his calculation on the Jensen model due to the ease of calculation of multiple wake interaction. He evaluated the wake interaction on a wind farm for three scenarios, as outlined below:

(1) Constant speed Wind from one direction

(2) Constant speed Wind from multiple directions

(3) Variable speed Wind from multiple directions

All the studies in this domain followed the $2 \times 2 \mathrm{~km}$ area plan of Mosetti [15]. It was clearly shown that the Jensen model was of much practical usage with the least computational effort. The prediction of the Jensen model held true for a good number of wind turbine installations and a reduction of cost by a factor of $1 / 3$ was seen for every new wind turbine included in the simulation.
This work was followed up by Grady [3] by the use of GAs for the solution of the WTO problem [3]. He reported better results as compared to Mosetti.

Improvements from Marmidis [16] followed and he used the Probabilistic Monte Carlo Simulation. Some significant results were also obtained by using modified objective function by Emami [17].

Then Mittal [16] used GA for the solution of the WTO problem and he evaluated the highest number of turbines that can be installed in a $2 \times 2 \mathrm{~km}$ area with the highest power at the least cost of installing such turbines [4].

Other wind turbine models are, the Fradsen model, the Fuga Model, the Larsen Model, The N.O. Jensen Model,the Ainslie Model and the UPMWAKE Model [1820].

The remainder of this paper has been organized as follows. The wind farm optimization problem is reviewed next in section 2. This is followed by the DEA that is elucidated in section 3. The DEA is followed by a discussion of the parameters used in section 4 . The data evaluation is carried out in section 5 and the conclusions are drawn in section 6 .

\section{THE WIND FARM OPTIMIZATION PROBLEM}

The Jensen model is used for evaluation of the multiple wake interaction behind turbines. The basic principle of conservation of momentum is utilized within multiple wakes. For the sake of simplification, it neglects the effects of turbulence in the near and far wakes [19].

In this model we consider the widely used basic assumptions in which Rotor radius is equal to $40 \mathrm{~m}$, the Hub height is equal to $60 \mathrm{~m}$, and the Thrust coefficient is equal to 0.88 [19]. 
The wake expands onwards by beginning at the rotor radius $r_{r}$, in a cone shaped trajectory in the wind direction and is denoted by $r_{1}$, at a distance of X from the rotor [19].

The wind speed is given by the equation (1); behind the rotor [19]:

$\mathrm{U}=\mathrm{u}_{0}+\left(1-\frac{2 \mathrm{a}}{1+\alpha\left(\frac{\mathrm{x}}{\mathrm{r}_{1}}\right)}\right)$

Where $\mathrm{U}$ is the wind speed behind the rotor (located at some finite distance, $\mathrm{X}, \mathrm{u}_{0}$ is the initial wind speed, $\mathrm{a}$ is the the axial induction factor, $a$ is the constant of entertainment, $\mathrm{X}$ is the distance and $\mathrm{r}_{1}$ is the wake radius [19].

Fig. 1 Illustrates the wake effect as a cone shaped phenomenon starting at the rotor with radius $r_{r}$ and expanding to $r_{1}$, at a distance of $X[19]$.

Where, $\mathrm{U}_{0}$ is the free stream wind speed. The following equation (2) gives the value of the axial induction factors as follows [19]:

$\mathrm{C}_{\mathrm{r}}=4 \mathrm{a}(1-\mathrm{a})$
Where, the wake radius is given by Equation (3), where X is the downstream distance from the turbine with radius $\mathrm{r}_{1}[19]$ :

$$
r_{1}=r_{r}^{2} \sqrt{\frac{1-a}{(1-2 a)}}
$$

Hence, $\mathrm{a}$, the entertainment constant, where $\mathrm{z}$ is the hub height (meters) and $\mathrm{z}_{0}$ is the factor of terrain roughness (meters) which is about 0.3 mfor flat lands [19], is given by equation (4):

$$
\alpha=\frac{0.5}{\ln \left(\frac{\mathrm{z}}{\mathrm{z}_{0}}\right)}
$$

The following equation gives the estimation of the wind speed and can be used to simulate multiple wakes located in tandem behind each another [19]:

$$
\mathrm{u}=\mathrm{u}_{0}\left[1-\sqrt{\sum_{\mathrm{i}=1}^{\mathrm{N}_{\mathrm{t}}}\left(1-\frac{\mathrm{u}_{\mathrm{i}}}{\mathrm{u}_{\mathrm{o}}}\right)^{2}}\right]
$$

In Equation (5), $\mathrm{N}_{\mathrm{t}}$ gives the total number of wind turbines in the particular wake vortex, $\mathrm{u}_{0}$ is the initial wind speed,

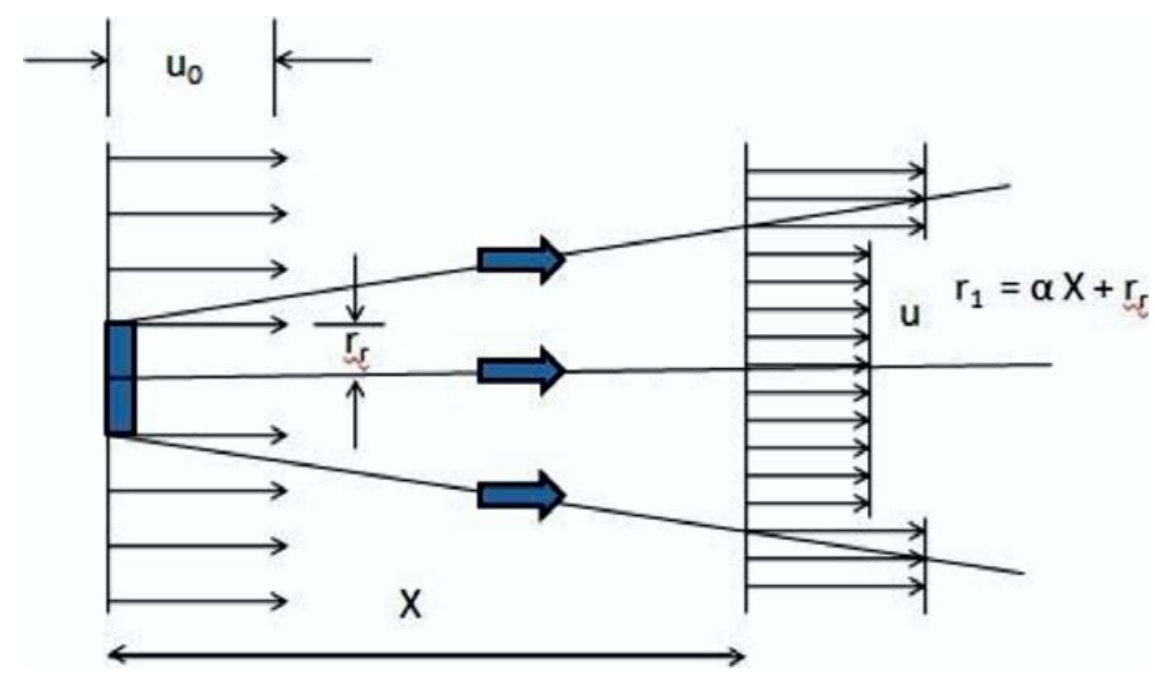

FIG. 1. WAKE EFFECT AS A CONE SHAPED PHENOMENON STARTING AT THE ROTOR 
$u_{i}$ is the $i^{\text {th }}$ turbine wind speed, and finally the factor $u$ gives the resultant wind speed after multiple wake interactions [19].

The Jensen model is useful for depicting the wake orders due to the placement of multiple turbines [19].

\subsection{Power Calculation Equations}

The Available Power is defined asequation (6) with reference to [19]:

Availale Power $=\frac{1}{2} \rho \mathrm{Au}^{3}$

By incorporating the efficiency parameter, ç [19],equation

(6) reduces to equation (7):

Availale Power $=\eta \frac{1}{2} \rho \mathrm{Au}^{3}$

Hence, we may solve to get equation (8):

Power Produced $=0.3 u^{3}$ Kilowatts

The optimization objective function for getting the maximum power is given in equation (9):

$\arg \max \sum \eta \frac{1}{2} \rho A u_{i}^{3}$

\subsection{Efficiency Calculations}

The Betz's limit gives the aerodynamic efficiency of the wind turbines as equation (10) [19]:

Efficiency, $\eta=\frac{\sum_{i=1}^{N_{t}} 0.3 \times u_{i}^{3}}{N_{t}\left(0.3 \times u_{o}^{3}\right)}$

Which may be written as equation (11):

Efficiency $=\frac{\text { Power }_{\text {Total }}}{\mathrm{N}_{\mathrm{t}}\left(0.3 \times \mathrm{u}_{\mathrm{o}}^{3}\right)}$

\section{Cost Model}

A non-dimensional classical cost model equation (12), is used for the purposes of this study. It decrements the cost by one third with the addition of every new turbine [19]:

$\arg \min \mathrm{N}_{\mathrm{t}}=\left(\frac{2}{3}+\frac{1 \mathrm{e}^{-0.00174} \mathrm{~N}_{\mathrm{t}}}{3}\right)$

Which is subject to:

$\mathrm{N}_{\mathrm{t}} \in\{0,100\}$

The cost model used in this study assumes that operating costs are negligible [19].

\section{THE DIFFERENTIAL EVOLUTION ALGORITHM (DEA)}

This algorithm is a Stochastic Direct Search Algorithm from the family of Evolutionary Algorithms. It is useful for determining the global maxima or minima in bounded domain. It is somewhat similar to GA, PSO (Particle Swarm Optimization), Evolutionary Strategy Algorithm and Evolutionary Programming Algorithms [20].

The general behaviour of the DEA can be deduced from [21], as the DEA has significant advantages over GA when compared in terms of:

(1) The speed of convergence of the algorithm

(2) The complexity of the code structure etc.

(3) The overall accuracy as compared from both algorithms by nearness to the optimal solution

(4) The stability of the solution set

In various studies, it has been demonstrated that the greatest advantage of using the DEA is that the sample space is continuously improved with each run of the algorithm so that the average solution at any instant is 
very close to the best solution. For a large sample size, convergence time of both the techniques is somewhat similar. However, the greatest advantage that the DEA technique offers is the stability of the solution. Moreover, the GA is known to falter for a less than optimal solution or a local optima due to premature convergence [21].

The DEA is much improved as compared to GA and other algorithms of the same class and is quoted in [22-24]. The DEA is robust and stable in problems having multiple dimensions, that are often multi-modal and have inherent noise that are otherwise tedious to resolve using other methods. The main reason for the use of the DEA is the Crossover Another impressive trait of differential evolution is that its parameters NP, CR and F are able to self-tune themselves in according to the requirements of the problem; a trait which is not available in other Metaheuristic Algorithms [25].

The DEA formulates its solutions on the basis of careful selection and then evaluation and finally by the process of recombination of the results. It is a self-adapting algorithm which is a crucial property that enables it to escape local minima or maxima very easily [26]. It takes three members of the species, takes a weighted difference of two of them and adds them to the third member to obtain a unique new member. The evaluation of the fitness of the new member introduced is done recursively with respect to the given objective function. The best member is selected on the basis of survival of the fittest and is hence a basic property of all evolutionary algorithms [20].

The DEA requires that the user properly configures the algorithm by appropriate representation, refining the selection process used and then setting the parameters of use [26]. Of these three processes the most important is the parameter setting which is of foremost concern before deploying the DEA [26].
It is also known as a directed parallel method of search. Therefore, the total population is denoted by NP each having D-Dimensions in each generation, [13]:

$x_{i, G} i=1,2,3, . . N P$

The DEA assumes that the NP remains the same during the iterative optimization process. It utilizes the Uniform Distribution to make the random guess about the next member of the population [13].

Hence, Uniform Distribution selects three members of the population and these are subjected to selective mutation and crossover to produce offspring. The process of selection yields the vector described by equation (13):

$\mathrm{x}_{\mathrm{i}, \mathrm{G}} \mathrm{i}=1,2,3, . . \mathrm{NP}$

which is mutated by the process stated in equation (14):

$\mathrm{v}_{\mathrm{i}, \mathrm{G}+1}=\mathrm{x}_{\mathrm{r} 1, \mathrm{G}}+\mathrm{F} \cdot\left(\mathrm{x}_{\mathrm{r} 2, \mathrm{G}-} \mathrm{x}_{\mathrm{r} 3, \mathrm{G}}\right)$

The following indexes $r_{1}, r_{2}, r_{3} \in\{1,2,3, \ldots N P\}$ of the mutation vector are two dimensional integers in our case. And it is given for a finite weighted value of $\mathrm{F}>0$ [13].

The DEA is further augmented by the use of crossover by having a trial vector:

$\mathrm{U}_{\mathrm{i}, \mathrm{G}+1}=\left(\mathrm{u}_{1 \mathrm{i}, \mathrm{G}+1}, \mathrm{u}_{2 \mathrm{i}, \mathrm{G}+1}, \ldots, \mathrm{u}_{\mathrm{Di}, \mathrm{G}+1}\right)$

Therefore,

$\mathrm{U}_{\mathrm{ji}, \mathrm{G}}+1=\left\{\begin{array}{c}\mathrm{v}_{\mathrm{ji}, \mathrm{G}+1} \text { if }(\operatorname{randb}(\mathrm{j}) \leq \mathrm{CRorj}=\operatorname{rnbr}(\mathrm{i}) \\ \mathrm{v}_{\mathrm{ji}, \mathrm{G}} \text { if }(\operatorname{randb}(\mathrm{j})>\text { CRorj } \neq \operatorname{mbr}(\mathrm{i})\end{array}\right\}$

$\mathrm{j}=1,2, \ldots, \mathrm{D}$

Hence, the DEA uses the function of $r$ and $b(j)$ to evaluate the value of the function in its jth value for a range of values between 1 and 0 . In addition the crossover constant, $\mathrm{CR}$ is evaluated between the value of 1 and 0 . Thus generating an index rnbr(i) that decides whether crossover takes place for a minimum of one species during the algorithm implementation [13]. 
The cost function is compared with the resultant vector $\mathrm{u}_{\mathrm{i}, \mathrm{G}+1}$ and with the initial vector $\mathrm{x}_{\mathrm{i}, \mathrm{G}}$. If there is an improvement in the value then the value of $u_{i, G+1}$ is carried over to the value of $x_{i, G+1}$ otherwise the historical value of $\mathrm{x}_{\mathrm{i}, \mathrm{G}}$ is kept [13].

This algorithm is often written as $(\mathrm{DE} / \mathrm{x} / \mathrm{y} / \mathrm{z})$, where $\mathrm{z}$ denotes the binary or exponential operator, $y$ shows the difference vector between two random members of the population and $\mathrm{x}$ shows the type of solution to be arrived at such as the random solution or the best solution. The most widely used configurations of DEA are (DE/rand/1/

*) and the (DE/Best/2/*) [20].

\section{PARAMETERS USED}

In our present study the results of the DEA have been compared with the results of GAs and have been categorized on the basis of [14]:

(1) Total Power dissipated

(2) Cost per unit power and the Cost per turbine

At the end of the simulation the results were obtained and matched with those of Rajper's work [14].

The values of the parameters for which the DEA code is run is as follows [14]:

$\mathrm{a}=0.326795$

$\alpha=0.09437$

$\mathrm{r}_{\mathrm{r}}=40 \mathrm{~m}$

$\mathrm{C}_{\mathrm{T}}=0.88$

$\mathrm{X}=200 \mathrm{~m}$

$\mathrm{U}_{0}=12 \mathrm{~m} / \mathrm{s}$

$\mathrm{Z}=60 \mathrm{~m}$

$\mathrm{Z}_{0}=0.3$

We have also followed the conventional cost analysis as also in Mittal [4] and Rajper [8] which is primarily done for the case of $U_{0}=12 \mathrm{~m} / \mathrm{s}$. The configuration of the DEA is done as follows:

Population size $(\mathbf{n P})=100$

Feed slave process $($ feedSlaveProc $)=5$

Maximum iterations $($ maxiter $)=900$

Maximum time $($ maxtime $)=900$

\section{DATA EVALUATION}

When the first turbine experiences a steady wind of $12 \mathrm{~m} / \mathrm{s}$ it derives a power of $518.4 \mathrm{~kW}$ at a standard cost at 0.0019279 and at a full efficiency equal to 1 . In our simulation the value of the efficiency decreases below the ideal value of 1 when the $14^{\text {th }}$ turbine is installed. This is a nominal dip in the value and the efficiency again reaches a value of 1 by the addition of the $15^{\text {th }}$ turbine to the simulation. This value then decrements by the installation of the $16^{\text {th }}$ turbine. From our simulation, it can be concluded that the power radiated from the turbines increases till the time the $81^{\text {st }}$ turbine is installed which is deemed to be the optimal number.

A comparison of the DEA and the GA reveals that the power generated reaches a higher value with the usage of the DEA (Fig. 2). This difference is evident by the time the $19^{\text {th }}$ turbine is installed. Hence, from the $20^{\text {th }}$ turbine and onwards the power difference is evident and the DEA performs better than GA.

A thorough comparison of the cost of using the both techniques reveals that the cost remains the same till the addition of the $15^{\text {th }}$ turbine to the simulation (Fig. 3). But, there is a marked difference from the $16^{\text {th }}$ to the $100^{\text {th }}$ turbine onwards. For the sake of simplification of the cost model the values are taken as non-dimensional or not in monetary terms like all the previous studies. It is also assumed that the operation and maintenance costs do not affect this calculation greatly. 
The maximum power that can be harnessed by using GA's [4] is till the time 54 turbines are introduced to the simulation but a maximum of 81 turbines can be inserted by using DEA. After the installation of these maximum turbines the power produced reduces from the maximum value.

Table 1 illustrates that it is possible to install more turbines by using the DEA in comparison to using the GA [14]. It is evident that more power can be reaped from the same area used by introducing 81 turbines.

TABLE 1. THE MAXIMUM COST TO POWER BY GA AND BY DEA

\begin{tabular}{|c|c|c|}
\hline & Genetic Algorithm & $\begin{array}{c}\text { Differential Evolution } \\
\text { Algorithm }\end{array}$ \\
\hline Number-of-Turbines & 54 & 81 \\
\hline Peak-Power-produced & $27,169.52$ & $40,700.84$ \\
\hline Cost-per-unit-power & 0.0013292 & 0.0013268 \\
\hline
\end{tabular}

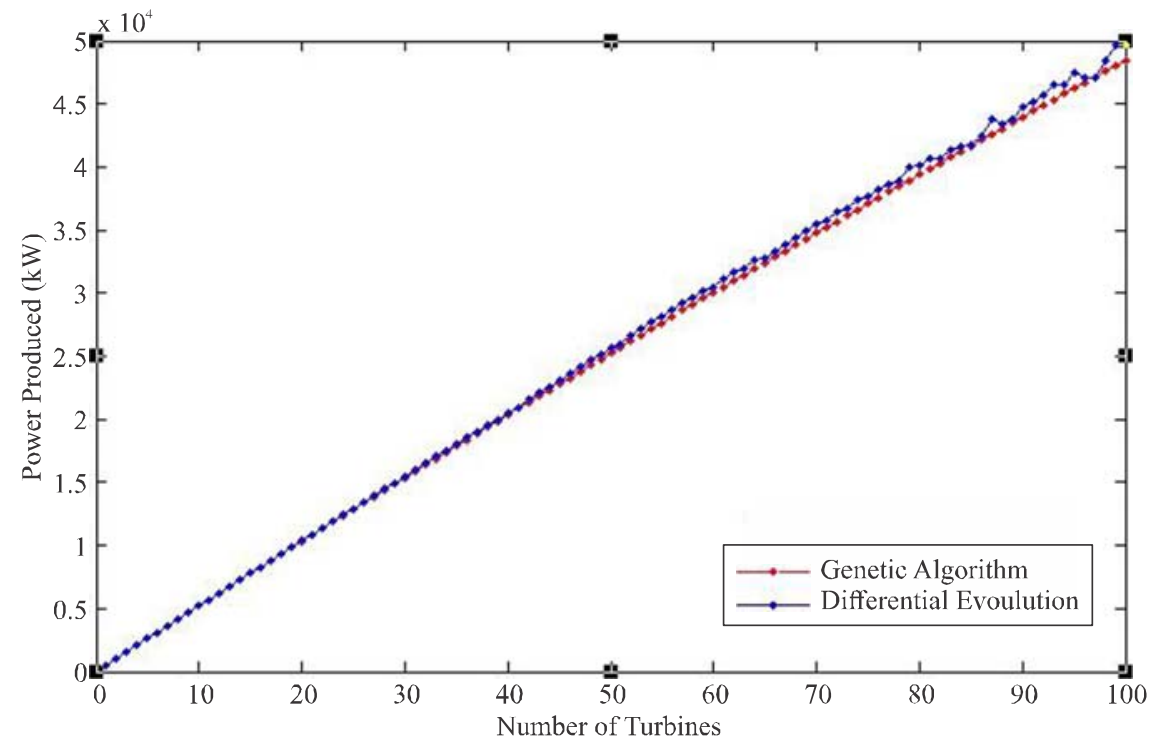

FIG. 2. THE POWER PRODUCED BY GA AND DEA

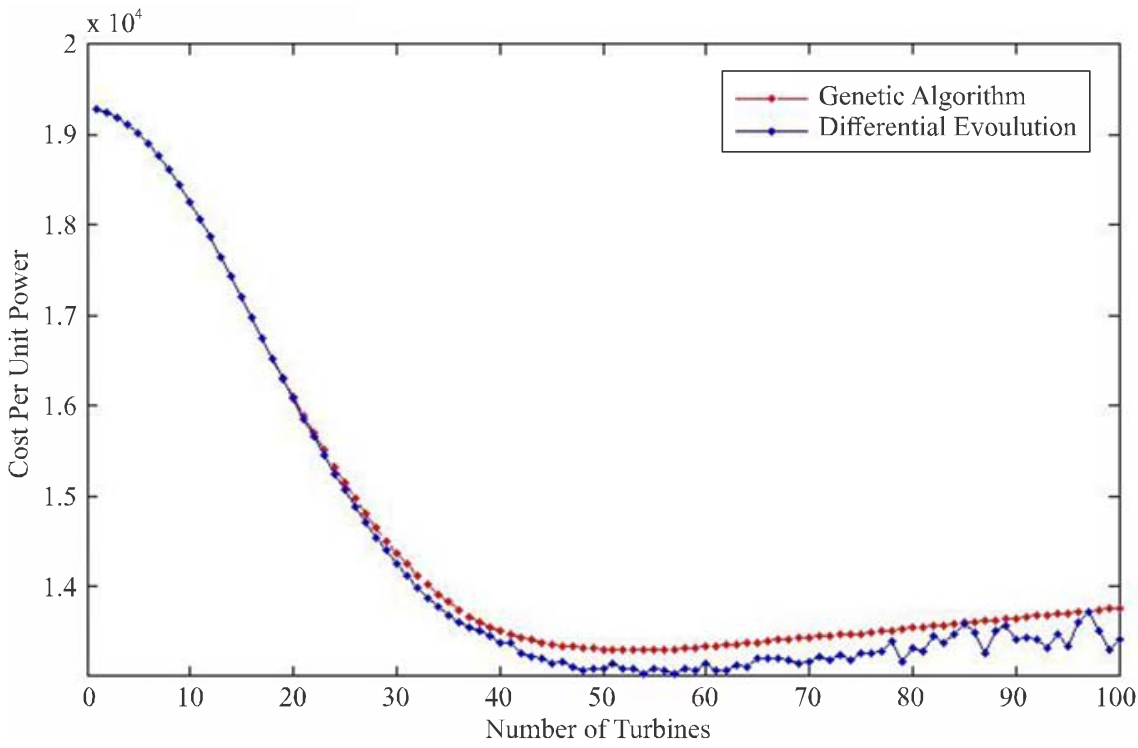

FIG. 3. THE COST ATTAINED BY USING GA AND BY THE DEA

Mehran University Research Journal of Engineering \& Technology, Volume 36, No. 2, April, 2017 [p-ISSN: 0254-7821, e-ISSN: 2413-7219] 
In Table 2 a comparison is drawn with the results obtained by Mosetti [15] and by the use of GA's [14] with our present study. This comparison is drawn at the installation of the $26^{\text {th }}$ turbine in the simulation. It is clearly evident that the DEA performs better than both the GA's and Mosetti's work [14-15]. For the peak power produced, the DEA returns a value of $13,448 \mathrm{~kW}$ as compared to 13,364 by the GA and 12,352 by Mosetti. However, in the case of the cost/objective function the value of DEA is 0.0014970 which is slightly higher than GA's at 0.001423 but in comparison it fares better than that of Mosetti at 0.0016197 . In the above comparison the efficiency of the DEA is the best at $99.7795 \%$, which is followed by GA's at $99.152 \%$ and by Mosetti at $91.645 \%$.

As per Table 3, a comparison of the work of Grady [3], GA's [14] and by using DEA is drawn. Again the power produced by the DEA is the highest at $15,502.19 \mathrm{~kW}$ followed by GA [14] at 15,372.49 and then by Grady [3] at $14,310.00$ at the instance when 30 turbines are functioning on the wind farm. However, the cost or the objective function value of GA's [14] is the lowest at 0.001423 followed by DEA at 0.0014249 and then by Grady [3] at 0.0015436 . But again the highest efficiency is achieved by the use of the DEA at $99.6797 \%$ followed by GA [14] at 98.846\% and Grady [3] at 92.015\%. Hence, it would be safe to conclude that the DEA outperforms both comparative approaches.

Similarly in Table 4, we may view the comparison of the three studies at the installation of 32 turbines. It is evident that the peak power produced is at its best value by using the DEA approach at $16,538.89 \mathrm{~kW}$ followed by Marmidis [16] at 16,395.00 and then by GA [14] at 16,376.65. Moreover, the cost or the objective function value by using the DEA is lowest at 0.0013985 followed

TABLE 2. COMPARISON OF GA [14], MOSETTI [15] AND THIS STUDY

\begin{tabular}{|c|c|c|c|}
\hline & Mosetti & Genetic Algorithm & Differential Evolution Algorithm \\
\hline Number-of-Turbines & 26 & 26 & 26 \\
\hline Peak-Power-produced-(kW) & 12,352 & $13,364.16$ & $13,448.68$ \\
\hline $\begin{array}{c}\text { Objective-function-value- } \\
\text { (by-use-of-Excel-Sheet) }\end{array}$ & - & 0.001497 & - \\
\hline Objective-function-value & 0.0016197 & 0.001423 & 0.0014970 \\
\hline Efficiency-(\%) & 91.645 & 99.152 & 99.7795 \\
\hline
\end{tabular}

TABLE 3. COMPARISON OF GA [14], GRADY [3], AND THIS STUDY

\begin{tabular}{|c|c|c|c|}
\hline & Grady & Genetic Algorithm & Differential Evolution Algorithm \\
\hline Number-of-Turbines & 30.0 & 30.0 & 30.0 \\
\hline Peak-Power-produced-(kW) & $14,310.00$ & $15,372.49$ & $15,502.19$ \\
\hline $\begin{array}{c}\text { Objective-function-value- } \\
\text { (by-use-of-Excel-Sheet) }\end{array}$ & - & 0.0014369 & - \\
\hline Objective-function-value & 0.0015436 & 0.001423 & 0.0014249 \\
\hline Efficiency-(\%) & 92.015 & 98.846 & 99.6797 \\
\hline
\end{tabular}

Mehran University Research Journal of Engineering \& Technology, Volume 36, No. 2, April, 2017 [p-ISSN: 0254-7821, e-ISSN: 2413-7219] 
by Marmidis [16] at 0.0014107 and by the use of GA's [14] at 0.001423. Last but not the least, the value of the efficiency of the DEA approach is the best at $99.6991 \%$ as compared to Mittal [4] which was not reported and GA's at $98.721 \%$.

Again in Table 5, it is evident that the DEA outperforms the comparative approaches at the introduction of the 44th turbine. The DEA reports a peak power of 22,600.06 $\mathrm{kW}$ at an objective function value of 0.0013203 and an efficiency of $99.0814 \%$, these values are the best in their respective categories. The GA [14] returns the second best value of 22,306 $\mathrm{kW}$ for the peak power produced and the third best value of the cost or the objective function at 0.001423 and the second best efficiency of $97.790 \%$. The results of Mittal [4] follow with the third best value of peak power produced at $21,936 \mathrm{~kW}$, with second best value of objective function at 0.0013602 and the third best value of efficiency at $96.100 \%$.
Fig. 4 depicts the final result of installation of 81 turbines in a $4 \mathrm{~km}^{2}$ area. The peak power produced is equal to $40,700.84$. This value is above the value of peak power of $40,670.61 \mathrm{~kW}$, after installing the next or 82 nd turbine.

The cost function behaves in a sporadic manner due to the inherent nature of the DEA but it is evident that its value remains lower as compared to GA, till the installation of the 100th turbine.

Thus the, Power, Cost and Efficiency of the same wind turbine may be compared at speeds of 6,8 and $10 \mathrm{~m} / \mathrm{s}$ to yield the following graphs.

Fig. 5, which depicts the Power produced illustrates the effect of wind speed on the power production of the wind turbines. Since the power produced is a function of the cube of the wind speed therefore, the higher the wind speed the more the power produced.

TABLE 4. COMPARISON OF GA [6], MARMIDIS [16], AND THIS STUDY

\begin{tabular}{|c|c|c|c|}
\hline & Marmidis & Genetic Algorithm & Differential Evolution Algorithm \\
\hline Number-of-Turbines & 32.0 & 32.0 & 32.0 \\
\hline Peak-Power-produced-(kW) & $16,395.00$ & $16,376.65$ & $16,538.89$ \\
\hline $\begin{array}{c}\text { Objective-function-value- } \\
\text { (by-use-of-Excel-Sheet) }\end{array}$ & - & 0.0014123 & - \\
\hline Objective-function-value & 0.0014107 & 0.001423 & 0.0013985 \\
\hline Efficiency-(\%) & Not reported & 98.721 & 99.6991 \\
\hline
\end{tabular}

TABLE 5. GA [6], MITTAL [4[AND THIS STUDY

\begin{tabular}{|c|c|c|c|}
\hline & Mittal & Genetic Algorithm & Differential Evolution Algorithm \\
\hline Number-of-Turbines & 44 & 44 & 44 \\
\hline Peak-Power-produced-(kW) & $21,936.00$ & $22,306.78$ & $22,600.06$ \\
\hline $\begin{array}{c}\text { Objective-function-value- } \\
\text { (by-use-of-Excel-Sheet) }\end{array}$ & - & 0.0013376 & - \\
\hline Objective-function-value & 0.0013602 & 0.001423 & 0.0013203 \\
\hline Efficiency-(\%) & 96.100 & 97.790 & 99.0814 \\
\hline
\end{tabular}

Mehran University Research Journal of Engineering \& Technology, Volume 36, No. 2, April, 2017 [p-ISSN: 0254-7821, e-ISSN: 2413-7219] 
Fig. 6 of cost produced illustrates the effect of wind speed on the cost of running such a facility. Since there are two types of cost involved in any wind power project, the first is the installation cost and the other is the operating cost. It can be seen that the effects of installation cost are lower after the installation of the $40^{\text {th }}$ turbine. After the installation of the $40^{\text {th }}$ turbine it becomes economical to add more turbines and the cost function levels off.

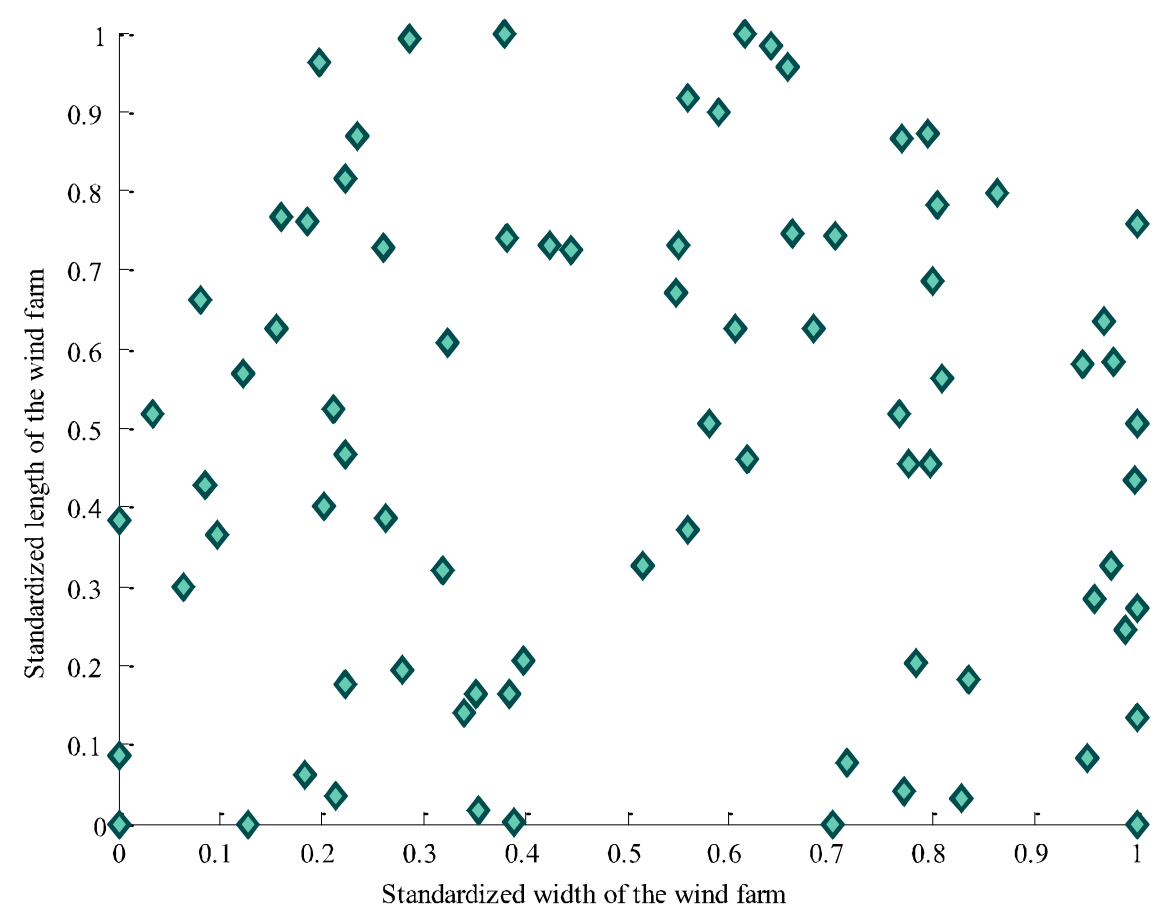

FIG. 4. OPTIMIZATION OF WIND TURBINES IN A STANDARDIZED AREA OF $2 \times 2 \mathrm{~km}^{2}$

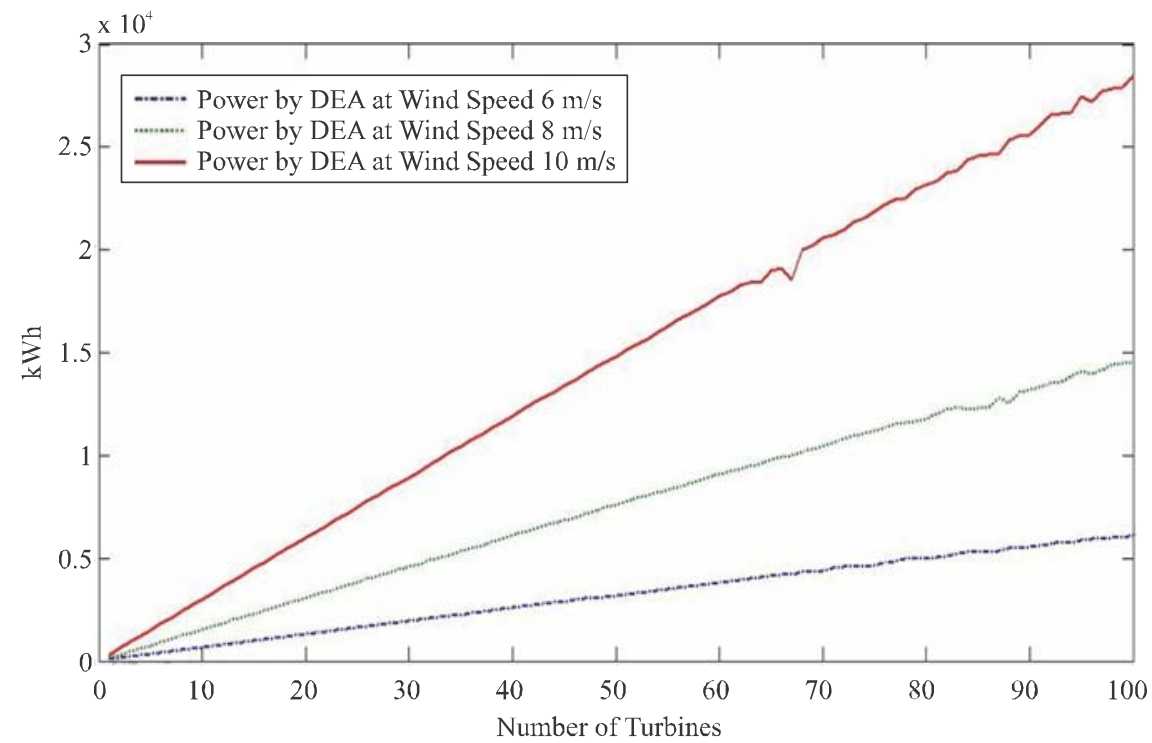

FIG. 5. COMPARISON OF POWER PRODUCED FOR 6, 8 AND $10 \mathrm{~m} / \mathrm{s}$ WIND SPEED

Mehran University Research Journal of Engineering \& Technology, Volume 36, No. 2, April, 2017 [p-ISSN: 0254-7821, e-ISSN: 2413-7219] 
Fig. 7 illustrates the effect of the stochastic nature of the DEA. It shows the variation in the results obtained as the simulation reports different values of efficiency depending upon the stochastic sequence generated by the computer.
Table 6 complete chart of the values of the peak power, the objective function and efficiency of the DEA and the GA's [14] is given for reference.

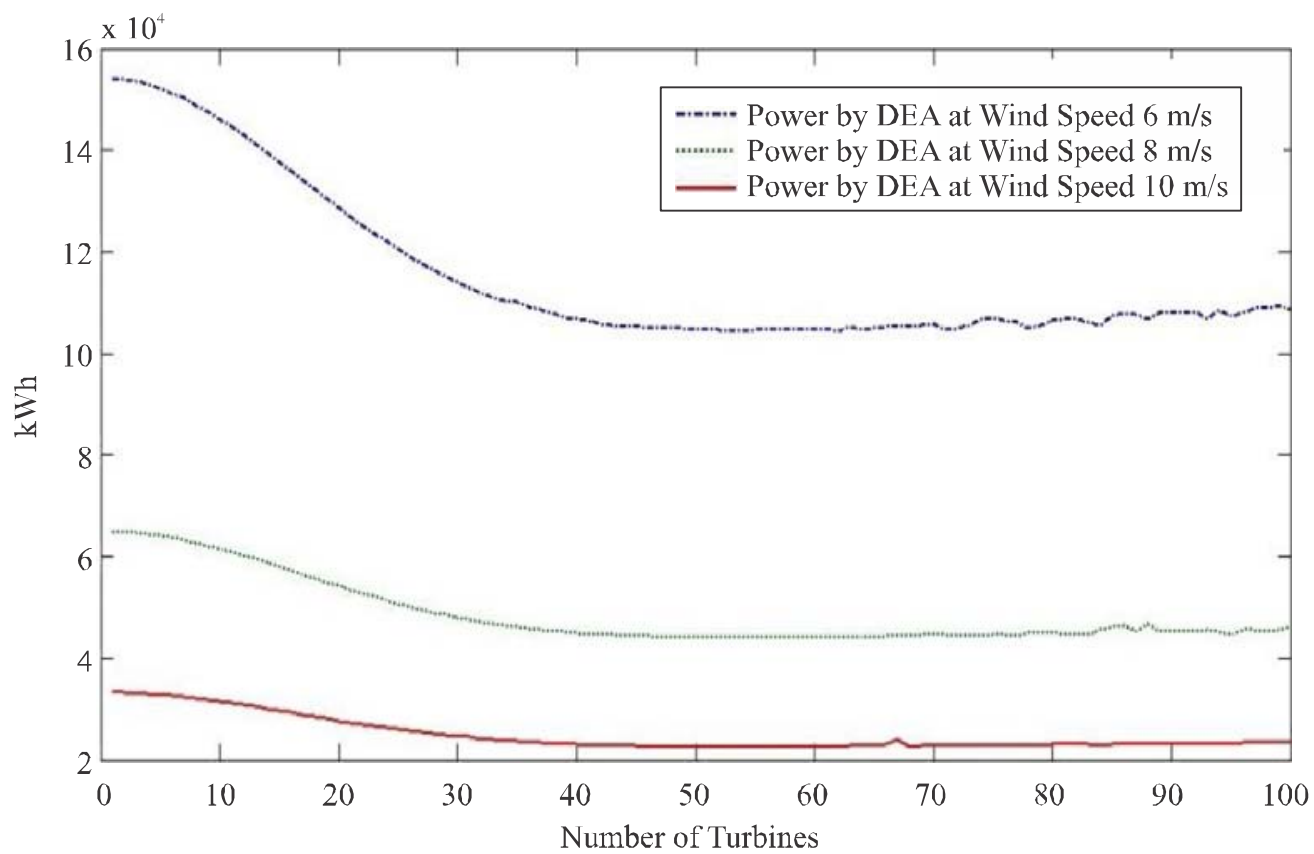

FIG. 6. COMPARISON OF COST FOR 6, 8 AND $10 \mathrm{~m} / \mathrm{s}$ WIND SPEED

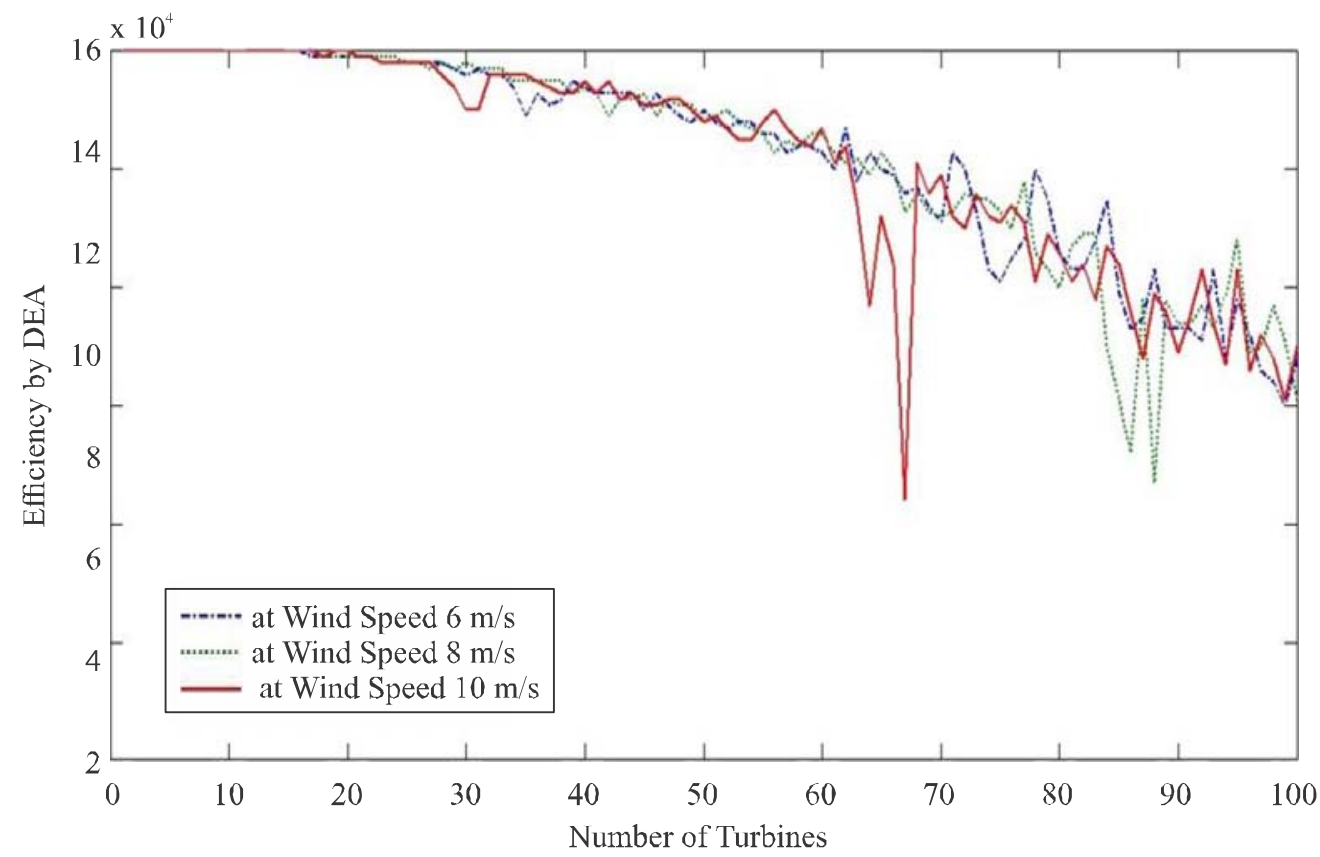

FIG. 7. COMPARISON OF EFFICIENCY FOR 6, 8 AND 10 M/S WIND SPEED 
Application of Differential Evolution for Wind Turbine Micrositing

TABLE 6. TOTAL POWER GENERATED AS WELL AS ITS COST

\begin{tabular}{|c|c|c|c|c|c|c|c|c|c|c|c|}
\hline No. of Turbine & Power by DE & Power by GA & Cost by DE & Cost by GA & Efficiency by DE & No. of Turbine & Power by $\mathrm{DE}$ & Power by GA & Cost by $\mathrm{DE}$ & Cost by GA & Efficiency by DE \\
\hline 1. & 518.4 & 518.40 & 0.0019279 & 0.0019279 & 1 & 51. & $26,016.96$ & $25,710.70$ & 0.0013139 & 0.0013296 & 0.984060 \\
\hline 2. & $1,036.8$ & $1,036.80$ & 0.0019246 & 0.0019246 & 1 & 52. & $26,625.47$ & $26,196.97$ & 0.0013079 & 0.0013293 & 0.987709 \\
\hline 3. & $1,555.2$ & $1,555.20$ & 0.0019190 & 0.0019190 & 1 & 53. & $27,116.55$ & $26,683.25$ & 0.0013079 & 0.0013292 & 0.986947 \\
\hline 4. & $2,073.6$ & $2,073.60$ & 0.0019114 & 0.0019114 & 1 & 54. & $27,706.40$ & $27,169.52$ & 0.0013034 & 0.0013292 & 0.989741 \\
\hline 5. & 2592 & $2,592.00$ & 0.0019016 & 0.0019016 & 1 & 55. & $28,084.34$ & $27,655.80$ & 0.0013090 & 0.0013293 & 0.985001 \\
\hline 6. & $3,110.4$ & $3,110.40$ & 0.0018899 & 0.0018900 & 1 & 56. & $28,635.46$ & $28,142.07$ & 0.0013065 & 0.0013294 & 0.986395 \\
\hline 7. & $3,628.8$ & $3,628.80$ & 0.0018764 & 0.0018765 & 1 & 57. & $29,224.14$ & $28,628.34$ & 0.0013026 & 0.0013297 & 0.989013 \\
\hline 8. & $4,147.2$ & $4,147.20$ & 0.0018612 & 0.0018613 & 1 & 58. & $29,605.24$ & $29,099.31$ & 0.0013079 & 0.0013307 & 0.984636 \\
\hline 9. & $4,665.59$ & $4,665.60$ & 0.0018444 & 0.0018445 & 1 & 59 & $30,138.19$ & $29,570.28$ & 0.0013066 & 0.0013317 & 0.985372 \\
\hline 10. & $5,183.99$ & $5,184.00$ & 0.0018263 & 0.0018263 & 1 & 60. & $30,467.18$ & $30,041.24$ & 0.0013141 & 0.0013328 & 0.979526 \\
\hline 11. & $5,702.39$ & $5,702.40$ & 0.0018069 & 0.0018069 & 1 & 61. & $31,149.41$ & $30,512.21$ & 0.0013065 & 0.0013338 & 0.985043 \\
\hline 12. & $6,220.79$ & $6,220.80$ & 0.0017864 & 0.0017865 & 1 & 62. & $31,633.49$ & $30,983.17$ & 0.0013074 & 0.0013349 & 0.984216 \\
\hline 13. & $6,739.19$ & $6,739.20$ & 0.0017651 & 0.0017652 & 1 & 63. & $32,002.59$ & $31,454.14$ & 0.0013131 & 0.0013359 & 0.979895 \\
\hline 14. & $7,256.05$ & $7,257.60$ & 0.0017435 & 0.0017432 & 0.999787 & 64. & $32,578.90$ & $31,925.11$ & 0.0013102 & 0.0013370 & 0.981955 \\
\hline 15. & $7,775.99$ & $7,776.00$ & 0.0017207 & 0.0017207 & 1 & 65. & $32,823.12$ & $32,396.07$ & 0.0013206 & 0.0013380 & 0.974095 \\
\hline 16. & $8,292.98$ & $8,294.40$ & 0.0016982 & 0.0016979 & 0.999829 & 66. & $33,359.45$ & $32,867.04$ & 0.0013193 & 0.0013391 & 0.975012 \\
\hline 17. & $8,809.73$ & $8,812.80$ & 0.0016755 & 0.0016749 & 0.999652 & 67. & $33,851.47$ & $33,338.00$ & 0.0013198 & 0.0013401 & 0.974626 \\
\hline 18. & $9,326.39$ & $9,331.20$ & 0.0016528 & 0.0016519 & 0.999484 & 68. & $34,395.80$ & $33,808.97$ & 0.0013182 & 0.0013411 & 0.975734 \\
\hline 19. & $9,841.61$ & $9,849.60$ & 0.0016304 & 0.0016291 & 0.999189 & 69. & $34,990.95$ & $34,279.94$ & 0.0013148 & 0.0013421 & 0.978232 \\
\hline 20. & $10,362.59$ & $10,351.68$ & 0.0016074 & 0.0016091 & 0.999478 & 70. & $35,449.87$ & $34,750.90$ & 0.0013165 & 0.0013430 & 0.976903 \\
\hline 21. & $10,881.62$ & $10,853.76$ & 0.0015852 & 0.0015893 & 0.999561 & 71. & $35,822.02$ & $35,221.87$ & 0.0013215 & 0.0013440 & 0.973255 \\
\hline 22. & $11,387.00$ & $11,355.84$ & 0.0015654 & 0.0015697 & 0.001565 & 72. & $36,393.53$ & $35,692.83$ & 0.0013190 & 0.0013449 & 0.975050 \\
\hline 23. & $11,902.21$ & $11,857.92$ & 0.0015449 & 0.0015506 & 0.998240 & 73. & $36,781.25$ & $36,163.80$ & 0.0013232 & 0.0013458 & 0.971938 \\
\hline 24. & $12,417.42$ & $12,360.00$ & 0.0015250 & 0.0015321 & 0.998056 & 74. & $37,433.83$ & $36,634.76$ & 0.0013179 & 0.0013467 & 0.975815 \\
\hline 25. & $12,931.86$ & $12,862.08$ & 0.0015060 & 0.0015142 & 0.997829 & 75. & $37,704.10$ & $37,105.73$ & 0.0013262 & 0.0013475 & 0.969756 \\
\hline 26. & $13,448.68$ & $13,364.16$ & 0.0014876 & 0.0014970 & 0.997795 & 76. & $38,204.72$ & $37,576.70$ & 0.0013262 & 0.0013484 & 0.969702 \\
\hline 27. & $13,969.24$ & $13,866.24$ & 0.0014698 & 0.0014807 & 0.998031 & 77. & $38,677.94$ & $38,032.84$ & 0.0013272 & 0.0013497 & 0.968964 \\
\hline 28. & $14,474.64$ & $14,368.32$ & 0.0014544 & 0.0014652 & 0.997206 & 78. & $38,849.36$ & $38,488.98$ & 0.0013385 & 0.0013511 & 0.960781 \\
\hline 29. & $14,984.48$ & $14,870.41$ & 0.0014395 & 0.0014506 & 0.996733 & 79. & $40,007.73$ & $38,945.12$ & 0.0013164 & 0.0013523 & 0.976904 \\
\hline 30. & $15,502.19$ & $15,372.49$ & 0.0014249 & 0.0014369 & 0.996797 & 80. & $40,061.22$ & $39,401.26$ & 0.0013313 & 0.0013536 & 0.965982 \\
\hline 31. & $16,021.05$ & $15,874.57$ & 0.0014111 & 0.0014241 & 0.996929 & 81. & $40,700.84$ & $39,857.40$ & 0.0013268 & 0.0013548 & 0.969289 \\
\hline 32. & $16,538.89$ & $16,376.65$ & 0.0013985 & 0.0014123 & 0.996991 & 82. & $40,670.61$ & $40,313.54$ & 0.0013441 & 0.0013560 & 0.956757 \\
\hline 33. & $17,055.61$ & $16,878.73$ & 0.0013869 & 0.0014014 & 0.996985 & 83. & $41,380.13$ & $40,769.68$ & 0.0013372 & 0.0013572 & 0.961720 \\
\hline 34. & $17,557.02$ & $17,380.81$ & 0.0013774 & 0.0013914 & 0.996109 & 84. & $41,607.52$ & $41,225.82$ & 0.0013459 & 0.0013584 & 0.955493 \\
\hline 35. & $18,077.95$ & $17,882.89$ & 0.0013673 & 0.0013822 & 0.996360 & 85. & $41,737.14$ & $41,681.96$ & 0.0013577 & 0.0013595 & 0.947194 \\
\hline 36. & $18,581.78$ & $18,384.97$ & 0.0013593 & 0.0013739 & 0.995680 & 86. & $42,488.45$ & $42,138.10$ & 0.0013494 & 0.0013606 & 0.953032 \\
\hline 37. & $19,062.79$ & $18,887.05$ & 0.0013537 & 0.0013663 & 0.993848 & 87. & $43,736.36$ & $42,594.24$ & 0.0013261 & 0.0013617 & 0.969747 \\
\hline 38. & $19,510.77$ & $19,389.13$ & 0.0013511 & 0.0013595 & 0.990434 & 88. & $43,440.03$ & $43,050.38$ & 0.0013505 & 0.0013627 & 0.952231 \\
\hline 39. & $20,024.30$ & $19,875.40$ & 0.0013444 & 0.0013545 & 0.990439 & 89. & $43,750.27$ & $43,506.51$ & 0.0013562 & 0.0013638 & 0.948256 \\
\hline 40. & $20,565.06$ & $20,361.68$ & 0.0013368 & 0.0013501 & 0.991756 & 90. & $44,773.83$ & $43,962.65$ & 0.0013401 & 0.0013648 & 0.959659 \\
\hline 41. & $20,976.86$ & $20,847.95$ & 0.0013380 & 0.0013463 & 0.986942 & 91. & 45187.69 & $44,418.79$ & 0.0013425 & 0.0013658 & 0.9578866 \\
\hline 42. & $21,602.70$ & $21,334.23$ & 0.0013262 & 0.0013429 & 0.992187 & 92. & $45,734.17$ & $44,874.93$ & 0.0013411 & 0.0013668 & 0.958932 \\
\hline 43. & $22,116.73$ & $21,820.50$ & 0.0013221 & 0.0013401 & 0.992173 & 93. & $46,533.57$ & $45,331.07$ & 0.0013324 & 0.0013677 & 0.965202 \\
\hline 44. & $22,600.06$ & $22,306.78$ & 0.0013203 & 0.0013376 & 0.990814 & 94. & $46,562.27$ & $45,787.21$ & 0.0013459 & 0.0013687 & 0.955523 \\
\hline 45. & $23,154.83$ & $22,793.05$ & 0.0013147 & 0.0013356 & 0.992577 & 95. & $47,525.01$ & $46,243.35$ & 0.0013326 & 0.0013696 & 0.965014 \\
\hline 46. & $23,605.94$ & $23,279.33$ & 0.0013155 & 0.0013339 & 0.989916 & 96. & $47,077.73$ & $46,685.14$ & 0.0013595 & 0.0013709 & 0.945974 \\
\hline 47. & $24,155.71$ & $23,765.60$ & 0.0013110 & 0.0013325 & 0.991418 & 97. & $47,121.59$ & $47,126.92$ & 0.0013723 & 0.0013722 & 0.937094 \\
\hline 48. & $24,709.37$ & $24,251.87$ & 0.0013068 & 0.0013315 & 0.993014 & 98. & $48,408.38$ & $47,568.70$ & 0.0013496 & 0.0013735 & 0.952861 \\
\hline 49. & $25,152.78$ & $24,738.15$ & 0.0013087 & 0.0013306 & 0.990205 & 99. & $49,636.67$ & $48,010.48$ & 0.0013297 & 0.0013747 & 0.967169 \\
\hline 50. & $25,625.21$ & $25,224.42$ & 0.0013092 & 0.0013300 & 0.988627 & 100. & $49,726.62$ & $48,452.26$ & 0.0013407 & 0.0013759 & 0.959233 \\
\hline
\end{tabular}

Mehran University Research Journal of Engineering \& Technology, Volume 36, No. 2, April, 2017 [p-ISSN: 0254-7821, e-ISSN: 2413-7219] 
The DEA approach is a stochastic one and has a faster convergence than the deterministic approach which describes the jumps in the algorithm results. The use of the DEA, rules out the manual approaches by application of the Finite Difference Method that would be tedious and almost impossible to compute given the vast number of calculations required.

It is concluded that the DEA approach used in this work and other recent approaches by firefly algorithm [1] and adjoint method [27] are better than the GAsand the finite difference methods [3]-[8] for Wind Farm Micrositing.

\section{CONCLUSIONS}

The performance of the DEA was evaluated as the number of turbines was increased. The DEA has proven itself to be robust and cost effective for the solution of this problem. The main feature of this algorithm is that it escapes local optima, multiple number of times during the running of this simulation. However, the small fluctuations in the values of the cost function can be eradicated by the use of extraneous computing power that results in an extensive search of the solution set.

It may be safely concluded that the DEA performs better as the number of turbines increases which is a quality of this algorithm reported in other applications. It may be concluded that the more the computing power the better and gradual results arise. Hence the DEA approach used in this work and other recent approachesare better than the GAs for Wind Farm Micrositing.

\section{ACKNOWLEDGEMENT}

Authors would like to thank and acknowledge the efforts and feedback received from Prof. Naeem-ul-Hassan Janjua, Dr. Riazuddin Abro, and the reviewers for their valuable comments that have led to the enrichment of this work.

\section{REFERENCES}

[1] Massan, S.-R., Wagan, A.I., Shaikh, M.M., and Abro, R., "Wind Turbine Micrositing by Using the Firefly Algorithm", Applied Soft Computing, November, 2014.

[2] Wikipedia, "Energypedia - Wind Energy - Introduction", 2014 [Online] Available: https://energypedia.info/wiki/ Wind_Energy_-_Introduction.

[3] Grady, S.A., Hussaini, M.Y., and Abdullah, M.M., "Placement of Wind Turbines using Genetic Algorithms", Renewable Energy, Volume 1, No. 30, pp. 259-270, 2005.

[4] Mittal, A., "Optimization of the Layout of Large Wind Farms Using Genetic Algorithm", MS Thesis, Department of Aerospace and Mechanical Engineering, Case Western Reserve University, USA, 2010.

[5] Barthelmie, R.J., Larsen, G.C., Frandsen, S.T., Folkerts, L., Rados, K., Pryor, S.C., Lange, B., and Schepers, G., "Comparison of Wake Model Simulations with Offshore Wind Turbine Wake Profiles Measured by Sodar", Journal of Atmospheric and Oceanic Technologies, Volume 23, pp. 888-901, 2006.

[6] Chen, Y., Li, H., Jin, K., and Song, Q., "Wind Farm Layout Optimization using Genetic Algorithm with Different Hub Height Wind Turbines", Volume 20, pp. 56-65, 2013.

[7] Chowdhury, S., Zhang, J., Messac, A., and Castillo, L., "Unrestricted Wind Farm Layout Optimization (UWFLO): Investigating Key Factors Influencing the Maximum Power Generation", Renewable Energy, Volume 38, No. 1, pp. 16-30.

[8] do Couto, T.G., Farias, B., Carlos, A., Diniz, G.C., Vinicius, M., and de Morais, G., "Optimization of Wind Farm Layout Using Genetic Algorithm", 10th World Congress on Structural and Multidisciplinary Optimization, pp. 1-10.

[9] Ituarte-Villarreal, C.M., and Espiritu, J.F., "Optimization of Wind Turbine Placement Using a Viral Based Optimization Algorithm”, Procedia Computer Science, Volume 6, pp. 469-474, 2011.

[10] Karampelas, P., Ekonomou, L., Fotis, G.P., and Vita, V., "Evaluation of the Optimal Number of Wind Turbines in a Wind Farm Using the Downhill Simplex Optimization Method", International Journal on Power System Optimization, Volume 3, No. 1, pp. 11-14. 
[11] Kusiak, A., and Song, Z., "Design of Wind Farm Layout for Maximum Wind Energy Capture", Renewable Energy, Volume 35, No. 3, pp. 685-694, March, 2010.

[12] Larsen, G.C., "A Simple Wake Calculation Procedure", RISO-M-2760.

[13] Storn, R., and Price, K., "Differential Evolution - A Simple and Efficient Heuristic for Global Optimization Over Continuous Spaces", Journal of Global Optimization, No. 11, pp. 341-359, 1997.

[14] Rajper, S., and Amin, I.J., "Optimization of Wind Turbine Micrositing: A Comparative Study", Renewable and Sustainable Energy Reviews, Volume 16, pp. 5485-5492.

[15] Mosetti, G., Poloni, C., and Diviacco, B., "Optimization of Wind Farms Positioning in Large Wind Farms by Means of a Genetic Algorithm", Wind Engineering and Industrial Aerodynamics, No. 51, pp. 105-116, 1994.

[16] Marmidis, G., Lazarou, S., and Pyrgioti, E., "Optimal Placement of Wind Turbines in a Wind Park Using Monte Carlo Simulation”, Renewable Energy, No. 33, pp. 1455-1460, 2008.

[17] Emami, A., and Nougreh, P., "New Approach on Optimization in Placement of Wind Turbines within Wind Farm by Genetic Algorithms", Renewable Energy, No. 35, pp. 169-178, 2010.

[18] Renkema, D.J., "Validation of Wind Turbine Wake Models - Using Wind Farm Data and Wind Tunnel Measurements", Delft University of Technology, Delft, Netherlands.

[19] Jensen, N.O., "A Note on Wind Generator Interaction", RISO-M-2411, 1983.
[20] Lee, J. B., "Clever Algorithms - Nature Inspired Programming Recipes”, Melbourne, Jason Brown Lee, 2011.

[21] Hegerty, B., Hung, C.-C., and Kasprak, K., “A Comparative Study on Differential Evolution and Genetic Algorithms for Some Combinatorial Problems", Southern Polytechnic State University, Marietta, GA

[22] Salcedo-Sanz, S., Xu, Y., and Yao, X., "Hybrid MetaHeuristics Algorithms for Task Assignment in Heterogeneous Computing Systems", Computers and Operations Research, Volume 33, No. 3, pp. 820-835, 2006.

[23] Codreanu, I., "Parallel between Differential Evolution and Genetic Algorithms with Exemplification in a Microfluidics Optimization Problem", Proceedings of International Conference on Semiconductor, pp. 421-424, 2005.

[24] Sentinella, M.R., "Comparison and Integrated use of Differential Evolution and Genetic Algorithms for Space Trajectory Optimization", IEEE Congress on Evolutionary Computation, pp. 973-978, 2007.

[25] Mezura-Montes, E., "Nature-Inspired Algorithms Evolutionary and Swarm Intelligence Approaches" A Tutorial in MICAI, 2008.

[26] Teo, J., "Exploring Dynamic Self-Adaptive Populations in Differential Evolution", Soft Computing, No. 10, pp. 673-686, 2006.

[27] Massan, S.R., Wagan, A.I., and Shaikh, M.M., "Power Optimization of Wind Turbines by the Adjoint Method", Sindh University Research Journal (Science Series), Volume 48, No. 3, pp. 559-562, Jamshoro, Pakistan, 2016. 